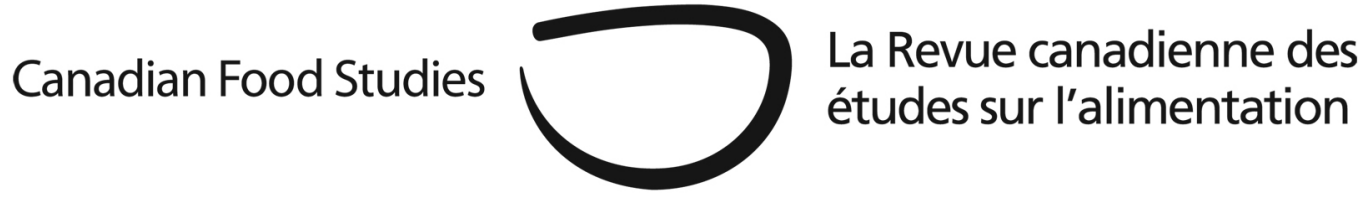

Field Report

\title{
Reflections of a food studies researcher: Connecting the community-university-policy divide...becoming the hyphens!
}

\author{
Lesley Frank \\ Department of Sociology, Acadia University, Wolfville, Nova Scotia, \\ lesley.frank@acadiau.ca
}

Having recently completed a doctorate degree, and settling into my new identity as a 'food studies' sociologist, I have been thinking a lot about my role as an academic researcher. I have a past life that has combined front-line food security work, community-based research, and public policy analysis. This means that I am well acquainted with what I call the community-universitypolicy divide. I am particularly aware of how the separation of these worlds can be problematic for progressive social change on matters of concern for citizens. In my experience, social problems and the effects of public policy for individuals, families, and communities are often not well understood by academics, who may have the resources to bring them to light with documented empirical evidence. In turn, those responsible for evidence-based policy making have limited capacity for research, and knowledge transfer of relevant research from the academy to policy realms and community is weak, to say the least (Stocking 1995). The divide between policy making and the micro-effects of policy is by far the widest.

My doctoral research on the relationship between family food insecurity and infant feeding clearly documented this divide. For example, food insecure mothers, who were primarily responsible for feeding their babies and families, were disconnected from, and had little or no input into, the policies that support or impede such work. Do food researchers have a role to play in bridging the divide between such experience and policy, so that experiences might be more fully recognized and integrated into food policy debates? The following discussion details the methods used in my research on infant food insecurity and provides a methodological reflection on this question. Ultimately it is a reflection on an unintentional outcome of research: the role of the researcher as storyteller, a role that can serve as the 'hyphens' in the community-universitypolicy divide. 


\section{Infant food insecurity}

My interest in the topic of infant food insecurity arose out of my years working as a coordinator of a Nova Scotia project called Great Beginnings in the 1990s. Great Beginnings was a project of the federally funded Canada Prenatal Nutrition Program (CPNP). Since 1995, CPNP has supported community-based projects throughout Canada to develop or enhance programs for vulnerable pregnant women, with the specific aim to "reduce the incidence of unhealthy birth weights, improve the health of both infant and mother and encourage breastfeeding” (Public Health Agency of Canada 2008). In this work I was confronted daily with the difficulties mothers experienced in maintaining breastfeeding and subsequently affording and having access to infant formula. In trying to feed, mothers and their babies were presented with problems of food production, food acquisition, food affordability, food safety, and food consumption. On the face of it, there was an apparent paradox: low-income mothers, who had difficulty affording infant formula, were the least likely to produce food via the breast. My job at the time was partially aimed at addressing this paradox, through targeted interventions, to increase breastfeeding rates to improve optimal infant nutrition. My frustrations in this job stemmed from a sociological awareness that this paradox was in fact not illogical. Low-income mothers faced a double burden when poverty conditions had an impact on breastfeeding success and optimal formula feeding. Years later, I conducted a case study to explore and unravel this paradox by examining the social, economic, and political relations that shaped food production via the breast and access to food for infants in general from the perspective of mother, as well as how infant food insecurity was conceived of and addressed by policy.

My approach to the study of public policy was integrative. I believe that the social world is best understood by exploring the interaction between micro-level experiences and objective social structures. I view the interconnections between public policy and experience in several key ways. First, policy as a component of the structures of governments and organizations shapes the social conditions within which we live. Second, while public policies are thought to be expressions of perceived social needs - created, enforced, and changing depending on these needs - they are in fact ideological. This means that public policy addresses and is shaped by dominant values held by the privileged in organizations of power, and can be part of the structures of inequality: serving to reinforce the current arrangements of society that benefit some at the expense of many. Policy is also created and enforced within the day-to-day working lives of policy enactors, leaving policy open to interpretation and various levels of compliance. Therefore, research on policy requires analysis of written and/or unwritten policies themselves (and the systems that support them) and an in-depth understanding of experience and perceptions of policy from a variety of perspectives. I suggest that such an integrative approach is ideally suited to food policy analysis. It has the potential to reveal the complexity of the social world and is a precondition to designing action for progressive change on food justice issues.

\section{The case study: A mixed methods approach for exploring the public policy relations of infant food insecurity}

I was interested in understanding the dynamics of the condition of infant food insecurity and the ways in which public policy does, does not, or could respond. I used a multi-phased, mixed methods research process to examine the everyday experiences of infant feeding under 
conditions of deprivation and the multiple policy domains that intersect with and shape those experiences. ${ }^{1}$

\section{Phase one: Exploring the everyday experiences of infant food insecurity}

I began by exploring the everyday experiences of infant food insecurity through the use of interviews with mothers living in low-income circumstances throughout Nova Scotia who had at least one child of at least six months and up to two years. This specification was set to ensure an adequate time frame to reflect on infant feeding experiences from birth up to the introduction of solid foods. The maximum age of two years was set to increase the likelihood that mothers would remember details concerning their experiences. Twenty in-depth, semi-structured, face-toface interviews took place from February to May 2011. Interview participants were selected in collaboration with projects of the Canada Prenatal Nutrition Program. In consultation with project coordinators, interviews were confirmed with twenty mothers living in twelve different communities in Nova Scotia. The exact settings of the interviews varied and were selected based on the preference of the interviewees. In all cases, family resource centres/projects were able to provide supports necessary to facilitate participation. Fifteen of the twenty interviews occurred within centres, where in-kind supports of transportation, childcare, and food were provided. Five interviews were conducted in the homes of interviewees at their request.

The interviews began with demographic questions such as age, number and age of children, schooling, family composition, income amount and source, and employment status. The majority of those interviewed were in their twenties. Seventeen mothers self-identified as white, two as aboriginal, and one as mixed. Two mothers had only one child, five had two children, and thirteen had three or more. Collectively the mothers had a total of sixty-one children ranging in age from five weeks to fifteen years. The median income of the group was less than $\$ 29,000$ annually and only one mother was currently working outside the home in a part-time job. Two mothers were on maternity leave and seventeen were not working. Nine mothers were parenting alone and all of them were receiving provincial income assistance. Seventeen of the twenty mothers had been on income assistance at some point during their experience as mothers.

General exploratory questions about social practice, social conditions and possible related external social relations (such as policy or local traditions) that could be playing a role in the experiences of families were posed. Interviewees discussed how decisions concerning infant feeding practice were influenced, experiences of infant feeding and food insecurity, strategies employed to address food insecurity and the role that policy and practice of institutions and governments do and/or could play in shaping infant food security and insecurity. An interview guide was used; however, interviewees were free to discuss any other topics they felt important, and discussions concerning the challenges of both parenting and poverty were common. The analysis of the interview transcripts resulted in three overall categories of experience concerning infant food insecurity: 1. How mothers used breastfeeding to produce infant food security, 2 . How breastfeeding was experienced as an insecure food system itself due to poverty environments and systematic barriers, and 3. How the unaffordability and inaccessibility of infant formula put infants at risk of food insecurity. Of particular interest was the analysis of the intersections between infant feeding experiences and household food insecurity. This phase of the research revealed how infant feeding, regardless of feeding method, was shaped by household food insecurity. Food access was compromised when lactation was shaped by mothers' material deprivation, institutional interference, and public attitudes against 
breastfeeding. Compromised food access was also apparent in alternatives to breastfeeding as low-income mothers were unable to purchase food commodities, and public policy and food charity systems were ill equipped to respond accordingly. ${ }^{2}$

\section{Phase two: Policy review}

Phase two began with the creation of a visual mapping of policy areas identified by mothers. Four sub-categories of policy thought to be essential for infant food security were identified shown below in Figure 1.

\section{Figure 1: Infant food insecurity policy map}

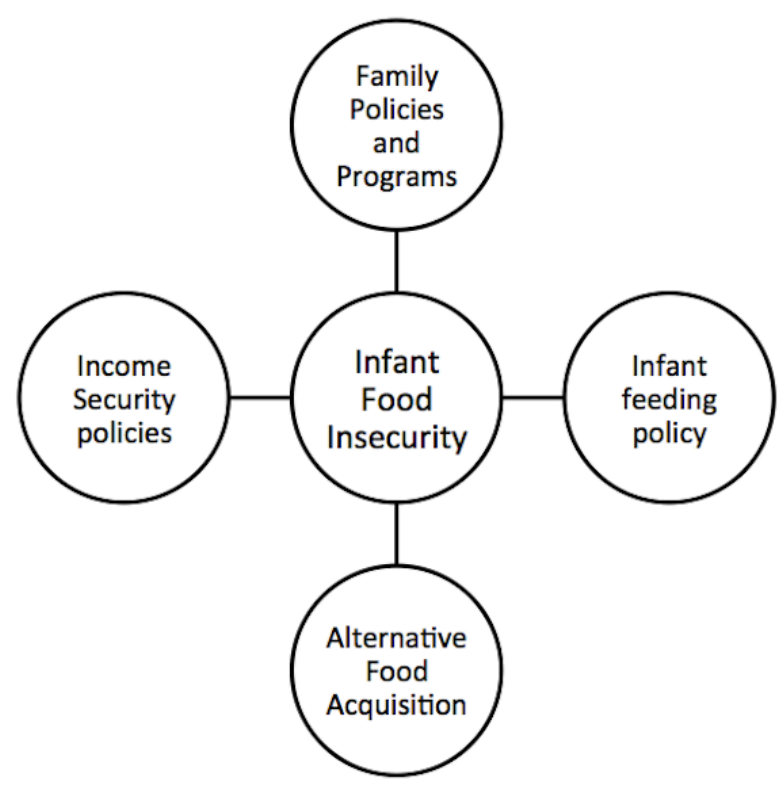

Document collection was conducted through the use of internet searches under the four headings of the policy map: family policies and programs; infant feeding/food policy and programs; alternative food acquisition; and income security. This process served as an environmental scan of relevant policies within the province of Nova Scotia. It also included relevant national policies and programs with an impact on Nova Scotians as well as wider international agreements in the keys areas of infant feeding and food security. After compiling electronic documents under the categorical structure of the policy map, each document was analyzed for specific relevance to infant food insecurity. In particular the analysis identified all intersections between infant feeding and the condition of food insecurity as well as noting if the policy had the potential to support food security or might lead to food insecurity for infants. Specific policies that were mentioned during the interviews were included, as were broader policy documents that were unknown and therefore not discussed by interviewees. ${ }^{3}$ In all, policies were documented at the community level, provincial level (beyond Nova Scotia for comparative purposes), and the national and international levels (in regard to international agreements that Canada has signed). A summary document was created which contained information on each of the four policy areas 
using three headings to record the following: key discussions from interviews; specific relevant policies (including a website address and excerpts of key importance); and policy-area cross references (identification of intersections among policy areas). Additionally, a detailed policy map was created to visually show the intersections between public policy that related to infant food insecurity, shown below in Figure 2.

\section{Figure 2: Infant food insecurity policy map (detailed)}

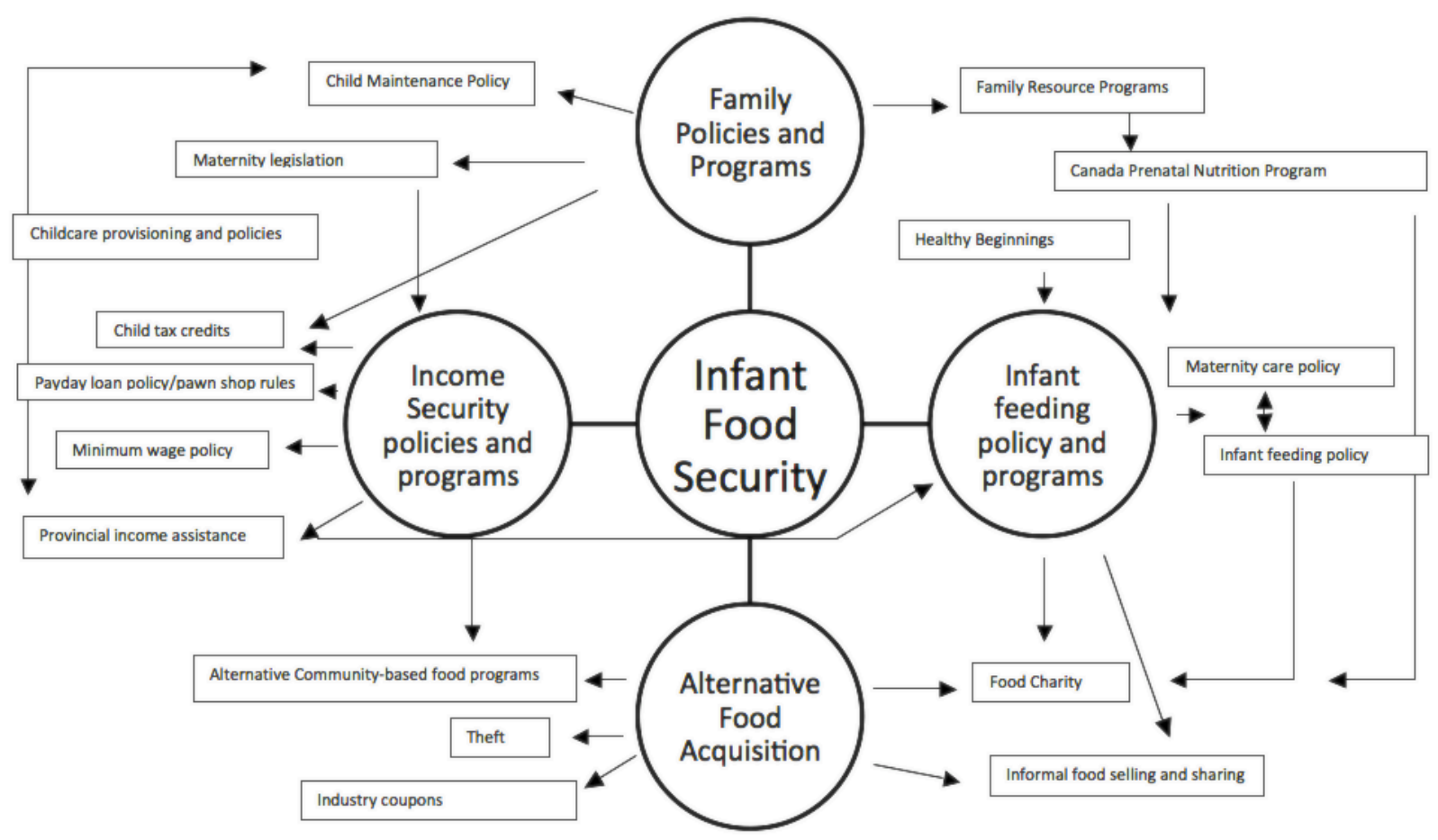

This summary document and the detailed policy map served as a tool for discussion and reflection during interviews with people in government and organizations with direct knowledge of the identified policy areas.

\section{Phase three: Interviews with policy and program workers}

Six formal interviews occurred between July and August of 2011 with staff in government and organizations with direct knowledge of the identified policy areas reviewed in phase two. Interviewees included three government employees (one provincial health and nutrition policy worker, one federal health policy worker, and one provincial community services policy worker) and three from community organizations working in the areas of family support, food security, and infant feeding. 


\section{Reflections on the policy interviews: data collection or story telling?}

The original intent of the interviews with policy workers was to collect data on the subjective meanings that staff attached to policy intent, experiences of enacting policy, perceived outcome for infant food insecurity and suggestions for improvements in the areas identified by the mothers. In a sense I was interested in data extraction from an alternative perspective in order to broadly explore infant food insecurity. However, when these interviews were completed and I was reading and analyzing transcripts, I was struck by how different the dialogue was between me (as the interviewer) and the interviewees (policy and program workers), as compared to the dialogue of the interviews I had conducted in the past. Generally I am pretty good at saying very little while soliciting peoples' stories. However, in this circumstance, my interview transcripts were filled with interviewer text. So much so that my hired transcriber admitted to wishing I would just "shut up", as she had heard these stories over and over and was tired of typing them. I commiserated with her, as I was initially unsatisfied with the interviews myself for the same reasons: quite frankly, I was irritated that I had talked so much. Being a sociologist who teaches qualitative research methods and interviewing techniques, I encourage my students to strive for maximizing the text produced from the interviewee and minimizing their own text. What had I done wrong? Why was I continually telling a story while the interviewee was listening? And what was the outcome of all this storytelling?

After a good deal of reflection, analysis of the interview transcripts, and insight from the policy workers themselves, I have come to see this interview experience as essential in understanding my role as a food studies researcher. Even though it was unintentional, I had become the hyphens! (that is, the hyphens in the community-university-policy divide). Instead of playing the role of facilitating information from the policy interviewees, I found myself playing the role of storyteller, conveying the stories told to me by the mothers to the workers of program and policy realms. This was the case because the complexity of infant food insecurity as a food/health policy issue was largely unknown and un-conceptualized within written policy and by policy workers. The interviews served the purposes of knowledge transfer of the women's stories, as the interviewees continued to ask me questions about many things that had not occurred to them before. The disjuncture between the everyday world of mothers and the world of policy decision-making was evident and in so, my storytelling of the micro-effects of policy was serving to connect mothers to the policy realms.

\section{The complexity of mother experiences of infant food insecurity}

Interviews with mothers identified infant food insecurity as a complex phenomenon that related to public policy in four key areas, illustrated by Figure 1. As Figure 2 detailed, there was a great deal of overlap and interconnection between the identified policy areas. For example, incomesecurity policy, such as provincial income-assistance policy, is a set of policies in which some are specific to income levels and others span issues of family policy (such as rules concerning child maintenance) or nutrition (such as entitlements for special diet requirements of infants and maternal nutrition allowances). Another example of overlap is seen in policies and programs that contribute to income security and that also constitute a position on family policy, such as the National Child Benefit or the Universal Childcare Benefit. Additionally, many policy discussions related to food charity rules (or payday loans or pawning) intersect with income security - but notably with the failure of income-security policy. Public policy also was 
manifested in mothers' lives through programs in which they participated, such as the Canada Prenatal Nutrition Program and public health services, particularly those shaped by infant feeding and nutrition policy.

Other than the two interviewees working directly in family support services (workers that were deeply involved in the complexity of infant feeding within poverty conditions), infant food insecurity as a social problem was largely un-conceptualized by policy enactors. Prior to the interviews, the complexity of the issue had not been considered and interviewees were only knowledgeable about areas of policy relevant to their work. For example, one senior policy analyst from community services remarked that she was struck by the complexity of infant food insecurity as represented in policy. She said:

So I was going through your chart, now, the Canada Prenatal Nutrition Program, that was a new one for me. I am familiar with Healthy Beginnings obviously, and I am familiar with infant feeding policy and those kinds of things, but there were things that I wasn't aware of. It appears, in some ways, that everything operates independent. If there could be more of the left hand knows what the right hand is doing, and maybe there is more happening than I know of because I do not know this in an in-depth kind of way, you know what I mean? If there could be more of a coordinated approach? ...I wonder how much everybody knows what everybody else is doing?

Other policy interviewees were surprised to hear about policies in other jurisdictions that mothers described as contributing to infant food insecurity. For example, the following health policy worker was shocked by an income assistance policy, and the community services policy worker was stunned by a mother's experience of needing to pray with volunteers prior to being giving infant formula from a charity organization:

Health policy worker: If I read that right, does that mean if I am a divorced mother and I am receiving child support from an expartner, and I am on income assistance, that child support is clawed back?

Researcher: Yes, dollar for dollar, it is considered non-earned income, and comes off your total entitlement.

Health policy worker: That is... I couldn't believe that, wow that is incredible. Personally it hit home for me, I just see that the rich get richer, and those that are already struggling are forced to grovel and beg.

Community Services policy worker: I was reading about some of the information you had there about food banks and how some have formula and some don't.

Researcher: Yes, food charity for babies was not anything mothers could rely on.

Community Services policy worker: It is like you have to pray it will be there. 
Researcher: Well in some cases women actually did have to pray, literally.

Community Services policy worker: Oh you mean pray, pray, really? Here in Nova Scotia, wow, that is a new one.

Another health policy worker (particularly in the area of infant feeding policy) was also unaware of informal food charity policies and practices concerning emergency formula provisioning within the community. Similarly the federal health policy worker was unaware of the status of food charity for infants. When asked, “do all of [food banks] stock formula?” I said:

Researcher: No, there are public asks for formula on many food bank websites across Canada but some believe Canadians should rethink donating formula to food banks as it might create barriers to breastfeeding. For example, INFACT Canada issued a press release in 2005 concerning this.

Health policy worker: You are kidding me? What right do they have to say that?

It was routine, as the interviewer, to answer questions about the state of infant food insecurity and the role policy played from the mother's perspective, particularly in the area of income assistance policy, family policy, food charity, and infant feeding - rather than the interviewee answering questions about the role of policy. This was most surprising when I attempted to secure an interview with the federal department responsible for the monitoring of Canada's Action Plan for Food Security. The written action plan outlines issues of food insecurity domestically and abroad with action priorities centered on improving food systems and food access. Infant feeding is briefly mentioned in this document as a food security concern, and the protection of breastfeeding is targeted as a key strategy for infant food security, particularly, but not only, in developing countries (Department of Agriculture and Agri-food 1998). When requesting an interview I was told that my interests were really a matter of infant feeding policy therefore regardless of the fact this department was responsible for monitoring Canada's Action Plan for Food Security, they would not have the expertise to discuss infant food insecurity. Clearly food insecurity was not conceptualized in the same way as it was by the mothers in my research. Although a formal interview did not take place, two civil servants from the department agreed to a phone call because they were interested to hear about infant food security policy from the perspective of mothers. In the conversation, they confirmed a lack of conceptualization of mothers' experiences of infant food insecurity, saying that they thought many government departments have not been made aware of the issue.

\section{Disjuncture between experiences of infant food insecurity and policy realms}

What is the connection between those who experience a social phenomenon and those who are tasked to shape, interpret, and implement public policy related to it? To begin, mothers' discussions about policy were very different than policy workers. The actual word policy was seldom used by the mothers interviewed. Rather, they talked about "rules" of various organizations' or government programs that they found either helpful or problematic. These were rules that were directly affecting them, and they tended to relate mostly to issues of income in a 
very broad sense-from income-assistance policy, government cash transfers, payday loans, pawning, maternity leave, and employment income, as well as family policy such as childcare and child support. As well, rules concerning charity food access, and (largely informal) institutional and community rules concerning infant feeding were prominent. It is also important to note that not all policy was experienced in formal and written ways, but it was experienced nonetheless. Policies that did not have any noticeable influence on mothers' daily lives (for example, the Nova Scotia Breastfeeding Policy) were unsurprisingly not named in their discussions. International, national, and even provincial policies (which by and large are policy positions, as opposed to legislated policy) were never discussed, and if they were (an example being Canada Child Tax Policy or the Canada Food Guide); there was little recognition that these were national policies as opposed to local policy. Just as mothers did not use the language of policy, they also did not use the language of food security or insecurity, nor for that matter infant feeding. They talked about not being able to feed their children, food bank rules, formula and breastfeeding, nurses, and community workers — often by their first names. They talked about things that create barriers to getting their life done and the things that facilitate living well.

As I have said above, some policy workers were quick to admit they did not fully understand how mothers were experiencing infant food insecurity. In other instances, policy workers attempted to explain the rationale of policy that they were familiar with that might be a barrier to infant food security. For example, policy enactors involved with infant feeding policy across the province highlighted problems within the health care system itself, anti-breastfeeding cultural norms, and the power of big business in the marketing of formula as the biggest challenges in their work of promoting and supporting breastfeeding. A family resource worker said, "I could talk for hours about the inadequacies of breastfeeding support in communities and this country," and the provincial health policy worker indicated that from her perspective, formula companies were the greatest culprit in creating infant food insecurity, as they have endless resources to promote the use of their products as an alternative means of feeding babies. She thought that such marketing power created an uphill battle for those working in setting policy and for those working directly with families in supporting breastfeeding.

Despite policy and support efforts, particularly in low-income populations, mothers' stories detailed how they relied on formula to feed their babies when breastfeeding was unsuccessful, and that in regard to this, it was very difficult to find help. Unknown to mothers, there is a provincial resource titled, How to Feed Your Baby with Infant Formula. When a policy worker was asked about this resource, she indicated that the guide was not accessible on the government website and was only distributed after an informed decision to formula feed was made during home visiting by public health staff. None of the mothers interviewed had ever received the guide (85\% of whom had used formula at some point). The guide tells you what you need to know to feed your baby as safely as possible and the approximate cost of formula. When I asked the policy worker if she felt that the timing (and method) of the distribution of this guide was effective in supporting mothers' needs, she said she "could argue both sides," meaning that it was effective in upholding the breastfeeding policy and in not bolstering the success of the formula industry, but that it had the potential to be ineffective if not readily available.

During my research, five staff members from four different family resource centres discussed the dilemma of providing support for formula feeding, a role they all described as a delicate balance of contradictions between breastfeeding policy, their own values as breastfeeding advocates, and the needs of low-income mothers. There appear to be contested ideas about how to respond to infant food insecurity within different policy and program realms. 
Government-funded programs and provincial infant-feeding policy does not address the need for emergency provisioning of infant formula. Yet those working closest with mothers in need of formula found secretive ways to respond. A policy worker interviewed discussed worries about the provincial breastfeeding policy, stating:

I do worry about the anxiety that the breastfeeding policy causes for the family resources centres and they do all they can to provide that supportive environment for women to try to breastfeed..., how do we support women for them to try on breastfeeding, if they don't want to do it, how do we help them get access to the proper developmental formula? We need to do both.... I think if the public health system is serious about going upstream then they have to be able to hear that and to be honest about what is really happening.

This same policy worker described this need to expose what is really happening due to a social disconnect between civil servants and citizens. For example, she felt an essential part of her own work was to listen to people's experiences and be a storyteller herself within government. She expressed how important is was for researchers to be sharing stories about what is happening on the ground, as she believed researchers provide credibility to her work in health equity policy. She said:

There is a social disconnect between civil servants and what is happening on the ground. The biggest thing is health practitioners just don't know to address poverty as a determinant of health, they don't know what is happening and they can't empathize. I believe so strongly in trying to lessen that social disconnect. My strategy is to truly listen. I learn about most of the policies impacting the families that we are talking about through my community friends and even just talking to you; then what I try to do with my learnings is talk to other civil servants, because we need to be enraged about some of these policies. For those that can be moved, we need to keep telling stories, giving examples, and we need to keep solidarity among those that care about equity. We need to be working with folks like you that are doing important things to make things credible, connected to reality; you are our lifeline, too, because I have very limited power.

This particular conversation is the one that spurred my reflection on my role of a food studies researcher. The finding of this case study revealed how infant feeding represents an example of food production, acquisition, and consumption that is rendered vulnerable by household food insecurity. Infants' access to food depended on a lactating mother or a reliable and affordable alternative. Compromised food access was also apparent in alternatives to breastfeeding, as lowincome mothers were unable to purchase food commodities. Regardless of infant feeding method, infants and their mothers were food insecure and public policy was partially at the root of this or was ill equipped to respond. If public policies are responses to social needs then we must fully understand what those needs are. The current disconnect between mothers’ 
experiences and the policy world will perpetuate this unknowing. An integrative approach to food studies research has the potential to make an account about what is really happening, and such accounts have the power to define what are considered real social problems. This is the precondition to designing action for progressive change on food justice issues, and why as a researcher “I just can’t shut up.”

\section{References}

Department of Agricultural and Agri-Food. (1998). Canada's action plan for food security. Retrieved April 15, 2009, from http://www.agr.gc.ca/index_e.php?s1=misb\&s2=fsecseca\&page=action

Public Health Agency of Canada. (2008). Retrieved at http://www.phac-aspc.gc.ca/hp-ps/dcadea/prog-ini/capc-pace/index-eng.php

Stocking, B. (1995). Why research findings are not used by commissions - and what can be done about it. Journal of public health medicine, 17(4): 380-382.

\footnotetext{
${ }^{1}$ I am indebted to the work of Canadian sociologist Dorothy Smith for informing my approach to sociological research, in particular her methodology of Institutional Ethnography, a research approach aimed at exploring the linkages between everyday experience and the extra-local social relations of organizations, governance and policy (See Smith, D. 2005. Institutional Ethnography; A Sociology for People. Lanham, MD: Altamira Press).

2 The results from this phase of the research are reported in a forthcoming publication by UBC Press to be completed in the fall of 2014.

${ }^{3}$ This was particularly so for any policy-related material that did not have any direct impact on the lives of mothers. For example, an income-assistance policy that impacts a mother's access to funding, or a food bank policy that restricts food access, is known, but provincial, national or international policy documents tended not to be.
} 